plate, each chemist should make experiments and decide which suits him best. All these reagents and methods have given good results in different hands, and men who are entirely successful with one, often have great difficulty in obtaining good results with some of the others.

For a full description of the details of the determination of zinc as pyrophosphate and for the ferrocyanise titration, see the paper by Mr. Waring in this Journal, 26, 9, (1904).

In conclusion we wish to express our thanks to all of those who have taken part in the work and without whose cordial co-operation it could not have been carried on.

(CONTRIBUtions From the Havemeyer Chemical, Laboratory, New York UNIVERSITY).

\title{
A NECESSARY MODIFICATION OF VOLHARD'S METHOD FOR THE DETERMINATION OF CHLORIDES. ${ }^{1}$
}

BY M. A. Rosanoff AND ARTHUR E. HIIL

Received December 14, 1906

\section{On the Determination of Chlorides.}

Volhard's method for the determination of chlorides is well known. It consists in acidifying the given solution with nitric acid, adding a ferric salt (say iron-ammonium alum) as an indicator, precipitating the chloride with a measured but excessive amount of a standard silver nitrate solution, and without filtering out the silver chloride, determining the excess of silver nitrate by titration with a standard solution of ammonium sulphocyanate. As long as the solution contains any silver, the ammonium sulphocyanate produces only a white precipitate of silver sulphocyanate. When the silver is goue, the solution is colored red by the sulphocyanate of iron.

A somewhat extensive experience in using this rapid method gradually forced upon us the feeling that in its present form it is inaccurate. The more carefully the titration is carried out, the less distinct the end-point often seems to be. A historical investigation showed that others have had similar experience with the method. Some time after the appearance of Volhard's first paper ${ }^{2}$ Brügelmann reported ${ }^{3}$ that the end point in question was indistinct, explaining it, however, on the assumption that it was the free nitric acid present that was destroying the color by oxidizing the sulphocyanate. The interfering factor was more clearly discerned by Drechsel, "who found that sulphocyanate of iron is decomposed

1 Presented before the New York Section of the Am. Chem. Soc., December 7 , I906.

${ }^{2}$ J. pr. Chem. 9, (N. F.) 217 (1874).

${ }^{3}$ Z. anal. Chem. 16, I (1877).

${ }^{4}$ J. pr. Chem., 15, I9I (I877) ; Z. anal. Chem. 16, 35I (I877). 
by the silver chloride first precipitated according to the following equation :

$$
\mathrm{Fe}(\mathrm{CNS})_{3}+3 \mathrm{AgCl}=\mathrm{FeCl}_{3}+3 \mathrm{AgCNS}
$$

He consequently recommended filtering out the silver chloride before titrating with sulphocyanate. Then appeared Volhard's exhaustive and final paper on the determination of silver and the halogens. ${ }^{1}$ Volhard, on the one hand, refutes Brügelmann's view and, on the other hand, maintains that the decomposition of dissolved sulphocyanates by solid silver chloride, pointed out by Drechsel, is too slow to interfere with the precision of the method. "Since," he says, "as mentioned, the decomposition of silver chloride by sulphocyanic acid or by a solution of ammonium sulphocyanate proceeds quite slowly, a liquid faintly colored by iron sulphocyanate is but very gradually decolorized by silver chloride $* * * *$ This renders it possible to determine, by means of sulphocyanate, the quantity of silver contained in a nitric acid solution in the presence as in the absence of silver chloride." Nevertheless, he urges extreme caution in looking for the end-point, that is, for the first appearance of a permanent coloration; for he had found that in the presence of some 0.4 gram silver chloride the very faint light-brown coloration first produced by the sulphocyanate failed to be intensified by the addition of eight more drops, accompanied by thorough shaking.

At present, analysts are not in agreement as to whether the precipitated silver chloride interferes or not with the sulphocyanate titration. Thus, to Sutton" "experience has proved that it is absolutely necessary to filter off the chloride and titrate the filtrate and washings." Similarly, in connection with a precise physico-chemical study $\mathrm{Knuipfer}^{3}$ found it necessary to filter off the silver chloride. He believes, however, that the action of silver chloride on sulphocyanates is "very slight" and that removing the chloride is necessary only in case of highly dilute solutions. BUT THE MAJORITY OF CHEMISTS CONSIDER THE REMOVAL OF THE CHLORIDE UNNECESSARY IN ANY CASE. Thus, Treadwel1 makes no mention at all of any possible interference by the silver chloride, nor does the United States Pharmacopoeia refer to it. Mohr and Classen ${ }^{5}$ state explicitly that the removal of the chloride is unnecessary and recommend Volhard's nethod in its original form. Finally, to quote one more authority, Fried-

${ }^{1}$ Liebig's Ann. 190, 8 (1878).

2"Volumetric Analysis" (Philadelphia, I904), footnote to p. 144.

" "Chemisches Gleichgewicht und elektromotorische Kraft" in Z. physik. Chem., 26, 266 (I898).

4 "Analytische Chemie", vol. 2, p. 5 Io (Leipzig and Vienna, 1905.)

${ }^{5}$ Mohr, edited by Classen, "Lehrbuch der chemisch-analytischen Titrimethode" (Braunschweig, I886), p. 403. 
heim ${ }^{1}$ directs : " $* * *$ And now, without filtering off the silver chloride, or even taking pains to cause it to coagulate by shaking (or boiling), sulphocyanate solution is added immediately, with continual stirring." In a footnote he emphasizes, with Volhard, the necessity of considerable training before the eye can discern the "true" end-point of the reaction.

In view of this conflict of statement, and of the value of a rapid method for determining chlorides, it seemed desirable to establish once for all, by systematic experiments, whether Volhard's method is reliable in its original form or requires modification.

The question to be answered was, Is the velocity of the reaction between solid silver chloride and dissolved sulphocyanates really as slow as it is generally supposed to be? While experience had taught us that it must be appreciable, special preliminary experiments soon indicated that it was astoundingly rapid ; for instance, about a gram of silver chloride shaken with an equivalent amount of iron sulphocyanate in dilute solution was all but completely transformed into silver sulphocyanate in a very few minutes. To obtain a reasonable percentage of change, and yet a reliable measurement of time, it seemed best to employ equivalent quantities of ammonium sulphocyanate and silver chloride and limit the time of the reaction to 2 minutes. The apparatus employed consisted of a cylindrical glass vessel with a wide delivery tube appropriately fused on near the bottom. The vessel was blackened on the outside and the delivery tube was closed by a piece of wide rubber hose and a pinch-cock. The silver chloride was kept distributed throughout the volume of the solution by means of a stirrer driven by a gas engine. The temperature of the reacting mixture was about $28^{\circ}$, and it varied by scarcely onetenth of a degree during the reaction. A good filter of glass wool and the use of a suction-pump permitted of removing a clear sample of about 50 c.c. for analysis in about 3 seconds. In each experiment, the silver chloride was prepared by precipitating, in a blackened flask, a known volume of standard silver nitrate solution with a slight excess of hydrochloric acid and carefully washing the coagulated precipitate by decantation. The precipitate was washed into the reaction-cylinder, water added to a I80 c.c. mark, an equivalent amount of ammonium sulphocyanate solution ( 20 c.c.) thrown in out of a test-tube, and the time noted. At the end of 120 seconds a sample was removed for analysis by opening the rubber hose of the delivery-tube directly over the glass wool filter.

The analytical method employed was as follows: An unmeasured volume of solution was precipitated by a known, excessive amount of silver nitrate. After filtering, the excess of silver was determined in the solution with standard ammonium sulphocyanate and an indicator of iron alum; this showed the total amount of silver precipitated. The mixed

1 "Leitfaden für quantitative chemische Analyse" (Berlin, 1897), p. I25. 
precipitate of $\mathrm{AgCl}$ and $\mathrm{AgCNS}$ was then transferred into an Erlenmeyer flask and boiled with an excess of concentrated nitric acid for $3 / 4$ of an hour (Borcher's method). Thereupon water was added, the silver chloride filtered off and the silver nitrate (from oxidized silver sulphocyanate) determined in the filtrate again by means of standard ammonium sulphocyanate and ferric salt; this showed the amount of silver originally precipitated as sulphocyanate.

Following are the results of three experiments :

\begin{tabular}{|c|c|c|c|c|c|c|}
\hline & $\begin{array}{l}\text { AgCl, } \\
\text { grams. }\end{array}$ & $\begin{array}{c}\mathrm{NH}_{4} \mathrm{CXS}, \\
\text { grams. }\end{array}$ & $\begin{array}{c}\text { Volume, } \\
\text { c.c. }\end{array}$ & $\begin{array}{l}\text { Temper- } \\
\text { ature. }\end{array}$ & $\begin{array}{l}\text { Time } \\
\text { seconds. }\end{array}$ & $\begin{array}{l}\text { Percentage } \\
\mathrm{NH}_{4} \mathrm{CNS} \text { changed } \\
\text { to } \mathrm{NH}_{4} \mathrm{Cl} \text {. }\end{array}$ \\
\hline I & 0.286 & 0.152 & 200 & $28.2^{\circ}$ & 120 & 45.6 \\
\hline 2 & 0.286 & O. I 52 & 200 & $28.4^{\circ}$ & 120 & 43.1 \\
\hline 3 & 0.286 & 0.152 & 200 & $28.3^{\circ}$ & 120 & 41.3 \\
\hline
\end{tabular}

The agreement of the results is more than sufficient for our purpose. But if the astonishing amount of 43 per cent. of sulphocyanate is destroyed by only an equivalent amount of silver chloride in 2 minutes, it must be expected that a large excess of the silver chloride (such as is present during a titration by Volhard's method) would destroy practically all the sulphocyanate in a few seconds. This was, in fact, shown by semi-quantitative experiments: amounts of silver chloride varying between 0.1 and 0.5 grams were uniformly found to destroy the iron sulphocyanate formed by 2 to ro drops of a $\mathrm{N} / 15 \mathrm{NH}_{4} \mathrm{CNS}$ solution in from 5 to ro seconds. The following observation is especially convincing : 0.5 gram of pure silver chloride was placed in 200 c.c. of water in a bottle, and 2 c.c. of a saturated solution of iron-ammonium alum were added; $1 / 2$ c.c. of a $\mathrm{N} / 15 \mathrm{NH}_{4} \mathrm{CNS}$ solution was then rapidly introduced from a burette, the bottle stoppered, and the whole vigorously shaken for ro seconds. The solution, originally deep-red, was now practically colorless : an "end-point" given by $\mathrm{I} / 2$ cubic centimeter of the reagent had disappeared in 10 seconds.

In view of these facts, the following analytical results, obtained by Volhard's method in its original and modified forms, respectively, will not appear surprising. First, a set of six determinations were carried out without filtering out the silver chloride (but.changing somewhat the rate of stirring). The chloride solution employed was found gravimetrically to contain $2.324 \mathrm{~g}$. of chlorine per litre. Found by Volhard's method:

$\begin{array}{ccc} & \text { C1 per litre in grams. } & \text { Relative error. } \\ \text { I } & 2.256 & -2.9 \% \\ 2 & 2.277 & -2.0 \\ 3 & 2.299 & -1.2 \\ 4 & 2.324 & -0.0 \\ 5 & 2.322 & -0.5 \\ 6 & 2.276 & -2.0\end{array}$


The same solution, precipitated with an excess of silver nitrate and filtered from the silver chloride gave uniformly excellent results :

$\begin{array}{ccc} & \text { Cl per litre in grams. } & \text { Relative error. } \\ \text { I } & 2.328 & +0.17 \% \\ 2 & 2.328 & +0.17 \% \\ 3 & 2.327 & +0.13\end{array}$

The conclusion is plain: Volhard's method for the determination of chlorides must be modified by filtering out the silver chloride. While this modification diminishes somewhat the rapidity of the method, it is under all conditions indispensable.

\section{On the Determination of Bromides and Iodides.}

We now turned to the determination of bromides. A solution made up of 200 c.c. of water, 2 c.c. of a saturated solution of iron alum, and I drop of a solution of $\mathrm{NH}_{4} \mathrm{CNS}$, was thrown upon $0.5 \mathrm{~g}$. silver bromide in a stoppered bottle and the mass vigorously shaken. After ro seconds no change of color was noticeable; after 30 seconds the color had become but slightly less intense. It seemed probable, therefore, that in ordinary titrimetric work the end-point would not be affected by the presence of solid bromide. This is, in fact, shown by the following four results, of which Nos. I and 2 were obtained by titration in presence of the bromide, Nos. 3 and 4 with the bromide filtered out.

$\begin{array}{llllll}\text { I } & \mathbf{5 . 3 6 6} & \text { g. } & \text { Br } & \text { per litre } \\ 2 & 5.366 & \text { " } & \text { " } & \text { " } & \text { " } \\ 3 & 5.357 & \text { “ } & \text { " } & \text { " } & \text { " } \\ 4 & 5.359 & \text { " } & \text { " } & \text { " }\end{array}$

The slight disparity of the results obviously lies within the limits of experimental error.

With reference to the determination of iodides, we have been unable to observe any diminution in the intensity of iron sulphocyanate coloration even after the colored solution had been shaken with silver iodide for one-half hour.

It is thus clear that in the determination of bromides and iodides it is unnecessary to filter out the silver precipitate before titrating with sulphocyanate.

\section{The End Point.}

The reactions between dissolved sulphocyanates and solid silver halides are, like all similar reactions, reversible. For instance,

$$
\mathrm{AgCl}+\overline{\mathrm{CNS}} \rightleftarrows \mathrm{AgCNS}+\overline{\mathrm{Cl}} \text {. }
$$

The transformation of sulphocyanates by silver chloride has been dis- 
cussed above. The opposite reaction may be readily demonstrated by shaking silver sulphocyanate with an ammonium chloride solution containing some iron-ammonium alum: dissolved sulphocyanate shows up in a very short time.

In equilibrium, $C_{\mathrm{Ag}}^{+} \cdot C_{\overline{\mathrm{Cl}}}^{-}=S^{2}{ }_{\mathrm{AgCl}}$ and $C_{\mathrm{Ag}}^{+} \cdot C_{\mathrm{CNS}}^{-}=S_{\mathrm{AgCNS}}{ }^{2}$, where $C$ stands for concentration and $S$ for solubility in pure water (both in mols. per litre). By division,

$$
\frac{C_{\mathrm{Cl}}^{--}}{C_{\mathrm{CNS}}^{-}}=\frac{S_{\mathrm{AgCl}}^{2}}{S_{\mathrm{AgCNS}^{2}}^{2}}
$$

Taking Böttger's ${ }^{1}$ recent solubility figures, $S_{\mathrm{AgCl}}=1.06 \cdot 10^{-5}$ and $S_{\mathrm{AgCNS}}$ $=8.27^{\prime} \mathrm{IO}^{-\rightarrow}$. Hence,

$$
\frac{C_{\tilde{\mathrm{Cl}}}}{C_{\mathrm{CXs}}}=\frac{\mathrm{I} .12 \cdot 10^{-10}}{6.84 \times 10^{-13}}=\text { about } 164 .
$$

Since similar salts are dissociated to the same degree, the ratio of the total (dissociated and undissociated) amounts of chloride and sulphocyanate in equilibrium with $\mathrm{AgCl}$ and $\mathrm{AgCNS}$ is also about 164 . $^{2}$ When, therefore, the ammonium sulphocyanate contained in a drop of solution is brought into contact with silver chloride, $\frac{164}{165}$ of it are transformed into chloride and only $\frac{I}{I 65}$ remains sulphocyanate. In other words, to produce the permanent colot-effect that a single drop of $\mathrm{NH}_{4} \mathrm{CNS}$ would have in the absence of $\mathrm{AgCl}$, no less than 165 drops of $\mathrm{NH}_{4} \mathrm{CNS}$ are required when $\mathrm{AgCl}$ is present. Such intensity of color is, however, unnecessary. We find that the eye can detect the coloration due to about $\mathrm{I} / \mathrm{I} 5$ of a drop of $\mathrm{N} / \mathrm{OONH}_{4} \mathrm{CNS}$ in $200 \mathrm{c.c}$. of water containing 5 c.c. saturated iron-alum solution. To establish such a coloration permanently in the presence of $\mathrm{AgCl}, \frac{\mathrm{I} 65}{\mathrm{I} 5}=\mathrm{II}$ drops of sulpho. cyanate solution are required. If the amount of silver nitrate required to precipitate the chloride in a given solution is about 25 c.c., the error committed in a perfect sulphocyanate titration in the presence of the silver chloride would amount to about $2 \%$. Ordinarily it will be smaller; the smaller, the less diligently one stirs the solution.

It might be similarly shown that in the case of bromides and iodides

${ }^{1}$ Z. physik. Chem. 46,602 (1903).

2 The general theory of such equilibria in salt solutions was first given by Nernst in his "Theoretische Chemie", Ed. I (Stuttgart, I893), p. 426. (Ed. 3, Stuttgart, I900, p. 498). 
the interference of the precipitates with the end-point is negligible. ${ }^{1}$ Dynamic theory is thus throughout in agreement with the verdict of our experiments.

NEW YoRk UNIVERSITY,

December, rgo6.

[CONTRIBUTION FROM THE LABORATORY OF THE MALIINCKRODT ChEMicaL, wORKS.]

\section{ON THE DIRECT QUANTITATIVE SEPARATION OF CHLORIDES AND BROMIDES}

By Launcelot W. ANDREWS

Received December 28 , 1906.

Introduction.

The direct separation of chlorine from bromine has always been considered one of the most difficult problems of quantitative analysis, excepting those relating to the rare earths and the radioactive elements. The standard works on quantitative analysis usually content themselves with a discussion of indirect methods, omitting any description of processes for direct separation.

Practically all the methods recommended for the direct separation of these elements rest on oxidation reactions applied to solutions of bromides and chlorides. The difference between the oxidation-potential of a solution of chlorine in potassium chloride and water, and that of a corresponding solution of bromine is about $0.24 \mathrm{I}$ volt. ${ }^{2}$ Numerous oxidizing agents have been employed, always in acid solution, that is in the presence of solutions more or less concentrated as regards hydrogen ions. In every case investigated, excepting one, the oxidant used possesses a higher oxidizing potential than that of an aqueous solution of chlorine. Hence in such cases, the success of the operation must depend on interrupting the process exactly at the point when all bromine is liberated, since if prolonged beyond that point, some chlorine would also be set free. Methods subject to conditions of this sort can not be looked upon

1 Taking Böttger's (loc. cit.) figures for the solubilities of $\mathrm{AgBr}$ and $\mathrm{AgCNS}$ and Kohlrausch and Dolezalek's figure (Ber. Berlin. Akad., rgor, p. ror) for the solubility of AgI, the ratios of the solubility-products involved are as follows:

$$
\frac{S^{2}{ }_{\mathrm{AgBr}}}{{S^{2}}_{\mathrm{AgCNS}}}=\frac{C_{\overline{\mathrm{BF}}}^{-}}{C_{\mathrm{CNS}}^{-}}=\frac{2.03 \cdot 10^{\mathrm{I}-3}}{6.84^{1} 10^{-\mathrm{I3}}}=\text { about } 0.3,
$$

(that is, of a drop of sulphocyanate added, $3 / \mathrm{I}_{3}$ will be changed to bromide, but $10 / 13$ will remain unchanged);

$$
\frac{S_{\mathrm{AgI}}^{2}}{S_{\mathrm{AgCNS}}^{2}}=\frac{C_{\bar{I}}}{C_{\mathrm{CNS}}}=\frac{2.25^{\cdot} 10^{-16}}{6.84^{1} 10^{-13}}=\text { about } 0.00033
$$

(that is, of a drop of sulphocyanate added, only about $1 / 3000$ will be changed to iodide).

${ }^{2}$ Bancroft, Z. phys. Chem. Io,405 (1892). 